\title{
EDITORIAL
}

\section{Relapse post hematopoietic SCT remains the Achilles heel for the field}

\author{
Bone Marrow Transplantation (2014) 49, 997-998; doi:10.1038/ \\ bmt.2014.134
}

Allogeneic hematopoietic SCT (HSCT) is a well-established treatment modality for patients with high-risk or relapsed hematologic malignancies. The main obstacles to successful HSCT in hematologic malignancies were outlined by E Donall Thomas in 1975 as the lack of suitable available donors, TRM and relapse post transplant. ${ }^{1,2}$ Since then there has been significant progress in addressing donor availability with the establishment of unrelated donor registries, the use of cord blood as a stem cell source and using haploidentical donors. ${ }^{3}$ Over the past two decades there has been substantial reduction in TRM secondary to improved supportive care and the introduction of reduced-intensity and non-myeloablative conditioning regimens for older patients and those with comorbidities. ${ }^{4}$ Despite all these advances there has been very limited progress in decreasing the incidence of relapse for patients with hematologic malignancies post HSCT. According to data from the Center for International Blood and Marrow Transplant Registry (CIBMTR), relapse is the leading cause of death for recipients of both related and unrelated donor transplant. Relapse contributes to $41 \%$ of the deaths in those receiving HLAidentical HSCT and 34\% in those receiving unrelated donor $\mathrm{HSCT}^{5}$

Recent studies have identified a group at high risk of relapse by evaluating the impact of minimal residual disease on the outcome post transplant in both ALL and AML., ${ }^{6,7}$ The risk of relapse is 2-3 fold higher in patients who are MRD positive pre-transplant, but patients who are MRD negative prior to HSCT have a relapse rate of $20-30 \%$. Although one in three patients will likely relapse following HSCT, physicians are left with no clear data to guide their management of those patients. Our ability to define a signature of graft-vs-tumor effect or the lack thereof has remained elusive. Thus, preemptive therapy post HSCT has remained limited to those suspected of having a high risk of relapse based on pretransplant characteristics of the disease using interventions primarily designed for the non-transplant patient. The interaction of these agents (viz. demethylating agents, tyrosine-kinase inhibitors, FLT-3 inhibitors) with the post-HSCT immune system, and potential drug interactions with immunosuppressive agents remain largely undefined.

Several studies have evaluated the outcome of patients with hematologic malignancies who relapse following allogeneic $\mathrm{HSCT}^{8-13}$ In a study by the Seattle group the authors reported on the outcome of 307 adult patients who relapsed following HSCT. The 2-year survival was 3-19\% depending on the time from transplant to relapse, with those experiencing relapse $>200$ days having the best outcome. ${ }^{12}$ In this study interventions did not include a second transplant. In a report by the European Society for Blood and Marrow Transplantation (EBMT) on the outcome of 465 adult patients with ALL, those who experienced post-HSCT relapse had a 5 -year OS of $1 \% .{ }^{13}$ Kurosawa et al. ${ }^{11}$ reported on 93 adult patients with hematologic malignancies who relapsed following allogeneic HSCT. Sixty-three patients underwent reinduction therapy and 27 (43\%) achieved a complete remission. Although the 1-year survival of those receiving a second transplant was better than that of those who did not $(51 \%$ vs $14 \%)$, the 2-year survival was not different. Similar results were observed in patients who experienced relapse following reduced intensity conditioning. ${ }^{9,10}$

In a recent study by our group we evaluated the outcome of 160 children with hematologic malignancies who relapsed following allogeneic HSCT. Forty-three (27\%) patients did not receive any salvage therapy and all of them died at a median of 1 month. One hundred and seventeen patients received salvage therapy and, interestingly, among the 78 patients with available detailed re-induction therapy 25 different regimens were used. ${ }^{8}$ The number of regimens used in those patients underscores the lack of uniform therapy for children who relapse following allogeneic HSCT. Unlike what has been observed in adult patients, pediatric patients who received a second HSCT had a significantly improved survival compared to those who were treated with salvage therapy without HSCT (35\% vs $2 \%) .^{8}$ It is also clear from our data that there is no consistent approach regarding the preparative regimen, intensity or timing of the second HSCT. A report from the CIBMTR on the outcome following second allogeneic HSCT in patients with acute and chronic leukemia found that patients younger than 20 years and those who relapse $>6$ months from the first HSCT have improved survival. ${ }^{14}$

In the current issue of the journal, Bejanyan et al. ${ }^{15}$ report on the clinical outcome of 104 patients with AML who experienced relapse after matched related and umbilical cord blood transplant. Thirty-seven (34\%) patients received supportive care and withdrawal of immune suppression and only one patient survived with no evidence of disease. Fifty-two (50\%) of the patients received intensive chemotherapy, with and without donor lymphocyte infusion or second HSCT. Although the remission rate was higher among those receiving DLI or second HSCT compared to those receiving chemotherapy alone, the 1-year survival was not different among those groups. Eighty-eight (85\%) patients died secondary to relapsed disease. This study, in addition to the prior published studies, underscores the lack of a unified and systematic approach to treating patients who experience relapse post transplant. Patients continue to receive variable chemotherapy approaches and some patients receive DLI while others receive second HSCT. The main challenges for treating posttransplant relapse are represented by the following questions:

1. What is the optimal chemotherapy induction regimen for patients who relapse post transplant? Unfortunately there are several restrictions on enrolling patients who experience relapse post HSCT on cooperative group- or industrysponsored relapsed studies. The eligibility criteria of many of those studies exclude patients who are early post transplant, those who are on immune suppression or patients with GVHD. When patients are enrolled and reported in such trials they are usually not analyzed separately regarding toxicity and outcome. There is a definite need for a prospective registry, or, more importantly, clinical trials dedicated to this patient population to study the toxicity and effectiveness of reinduction chemotherapy. The molecular heterogeneity of AML needs to be studied in this patient population to better identify the role of genotypic targeted therapy. Patients achieving CR generally have full donor engraftment and some patients develop GVHD upon recovery post induction. Hence patients treated with re-induction chemotherapy should be 
monitored for GVHD that occasionally can be attributed mistakenly to re-induction toxicity.

2. What is the role of DLI and 2nd HSCT? There are no randomized or large prospective trials addressing the role of DLI either as primary therapy or as post-induction consolidation therapy. In the study in this issue patients receiving DLI seemed to have improved CR but not OS. When using DLI it is not clear what is the right timing or dosing or schedule of DLI. It is also not clear if DLI has a role as a prophylactic treatment post re-induction therapy, and the risk of developing severe GVHD in this setting is not known. With increased use of cord blood as a stem cell source the use of DLI is not an option. Although third-party viral-specific T-cell therapies have been successfully used to treat post-transplant viral infection, well-matched thirdparty DLI has not been used to treat post-transplant relapse. ${ }^{16}$ Some studies have shown that a second transplant can provide improved remission and OS, but all those studies were retrospective and treating physician bias cannot be ruled out as a contributing factor. $8,9,11,17$

3. What is the role of targeted immune therapy? Recent studies have investigated the role of chimeric antigen receptormodified T cells in relapsed and refractory ALL, with preliminary results showing impressive results in patients who have relapse post allogeneic HSCT without increasing the risk of GVHD. ${ }^{18,19}$ Multicenter trials are planned to evaluate this therapy in relapsed patients, including those with post-transplant relapse. Although this therapy is currently limited to patients with ALL, effort is ongoing to widen its indications to other hematologic malignancies.

The National Cancer Institute has sponsored 2 international workshops on the biology, prevention and treatment of relapse following allogeneic HSCT. The committee acknowledged that there are several confounding factors and a lack of clinical studies. ${ }^{20,21}$ Although the most of the focus was on preventing relapse, the committee reported on potential advances in using novel cellular therapies to address relapse. The committee acknowledged the need for prospective well-designed international studies to address the best way to manage posttransplant relapse.

In conclusion, relapse continues to be a major obstacle in the success of allogeneic HSCT for hematologic malignancies. The study in this issue of the journal adds to the published data that there is an urgent need to address the issue of managing relapse post HSCT.

\section{CONFLICT OF INTEREST}

The authors declare no conflict of interest.

$\mathrm{H}_{\text {Frangoul }}{ }^{1}$ and $M$ Jagasia $^{2}$

${ }^{1}$ Pediatric Stem Cell Transplant Program, Monroe Carell Jr. Children's Hospital at Vanderbilt, Vanderbilt University, Nashville, TN, USA and

${ }^{2}$ Division of Hematology-Oncology, Department of Medicine, Vanderbilt University, Nashville, TN, USA E-mail: Haydar.Frangoul@vanderbilt.edu

\section{REFERENCES}

1 Thomas E, Storb R, Clift RA, Fefer A, Johnson FL, Neiman PE et al. Bone-marrow transplantation (first of two parts). New Engl J Med 1975; 292: 832-843.

2 Thomas ED, Storb R, Clift RA, Fefer A, Johnson L, Neiman PE et al. Bone-marrow transplantation (second of two parts). New Engl J Med 1975; 292: 895-902.
3 Copelan EA. Hematopoietic stem-cell transplantation. New Engl J Med 2006; 354 1813-1826.

4 Gooley TA, Chien JW, Pergam SA, Hingorani S, Sorror ML, Boeckh M et al. Reduced mortality after allogeneic hematopoietic-cell transplantation. New Engl J Med 2010; 363: 2091-2101.

5 van den Brink MR, Porter DL, Giralt S, Lu SX, Jenq RR, Hanash A et al. Relapse after allogeneic hematopoietic cell therapy. Biol Blood Marrow Transplant 2010; 16: S138-S145.

6 Pulsipher MA, Langholz B, Wall DA, Schultz KR, Bunin N, Carroll WL et al. The addition of sirolimus to tacrolimus/methotrexate GVHD prophylaxis in children with ALL: a phase 3 Children's Oncology Group/Pediatric Blood and Marrow Transplant Consortium trial. Blood 2014; 123: 2017-2025.

7 Walter RB, Buckley SA, Pagel JM, Wood BL, Storer BE, Sandmaier BM et al. Significance of minimal residual disease before myeloablative allogeneic hematopoietic cell transplantation for AML in first and second complete remission. Blood 2013; 122: 1813-1821.

8 Bajwa R, Schechter T, Soni S, Gassas A, Doyle J, Sisler I et al. Outcome of children who experience disease relapse following allogeneic hematopoietic SCT for hematologic malignancies. Bone Marrow Transplant 2013; 48: 661-665.

9 Bethge WA, Storer BE, Maris MB, Flowers ME, Maloney DG, Chauncey TR et al. Relapse or progression after hematopoietic cell transplantation using nonmyeloablative conditioning: effect of interventions on outcome. Exp Hematol 2003; 31: 974-980.

10 Kobayashi K, Kami M, Murashige N, Kusumi E, Kishi Y, Hamaki T et al. Outcomes of patients with acute leukaemia who relapsed after reduced-intensity stem cell transplantation from HLA-identical or one antigen-mismatched related donors. Br J Haematol 2005; 129: 795-802.

11 Kurosawa S, Fukuda T, Tajima K, Saito B, Fuji S, Yokoyama H et al. Outcome of 93 patients with relapse or progression following allogeneic hematopoietic cell transplantation. Am J Hematol 2009; 84: 815-820.

12 Mielcarek M, Storer BE, Flowers ME, Storb R, Sandmaier BM, Martin PJ. Outcomes among patients with recurrent high-risk hematologic malignancies after allogeneic hematopoietic cell transplantation. Biol Blood Marrow Transplant 2007; 13: $1160-1168$.

13 Spyridonidis A, Labopin M, Schmid C, Volin L, Yakoub-Agha I, Stadler M et al. Outcomes and prognostic factors of adults with acute lymphoblastic leukemia who relapse after allogeneic hematopoietic cell transplantation. An analysis on behalf of the Acute Leukemia Working Party of EBMT. Leukemia 2012; 26: 1211-1217.

14 Eapen M, Giralt SA, Horowitz MM, Klein JP, Wagner JE, Zhang MJ et al. Second transplant for acute and chronic leukemia relapsing after first HLA-identical sibling transplant. Bone Marrow Transplant 2004; 34: 721-727.

15 Bejanyan N, Oran B, Shanley R, Warlick E, Ustun C, Vercellotti G et al. Clinical outcomes of AML patients relapsing after matched-related donor and umbilical cord blood transplantation. Bone Marrow Transplant 2014; 49: 1029-1035

16 Eiz-Vesper B, Maecker-Kolhoff B, Blasczyk R. Adoptive T-cell immunotherapy from third-party donors: characterization of donors and set up of a T-cell donor reg istry. Front Immunol 2012; 3: 410.

17 Michallet M, Tanguy ML, Socie G, Thiebaut A, Belhabri A, Milpied N et al. Second allogeneic haematopoietic stem cell transplantation in relapsed acute and chronic leukaemias for patients who underwent a first allogeneic bone marrow transplantation: a survey of the Societe Francaise de Greffe de moelle (SFGM). Br J Haematol 2000; 108: 400-407.

18 Brentjens RJ, Davila ML, Riviere I, Park J, Wang X, Cowell LG et al. CD19-targeted $T$ cells rapidly induce molecular remissions in adults with chemotherapyrefractory acute lymphoblastic leukemia. Science Transl Med 2013; 5177ra38.

19 Grupp SA, Kalos M, Barrett D, Aplenc R, Porter DL, Rheingold SR et al. Chimeric antigen receptor-modified T cells for acute lymphoid leukemia. New Engl J Med 2013; 368: 1509-1518.

20 de Lima M, Porter DL, Battiwalla M, Bishop MR, Giralt SA, Hardy NM et al. Proceedings from the National Cancer Institute's Second International Workshop on the Biology, Prevention, and Treatment of Relapse After Hematopoietic Stem Cell Transplantation: Part III. Prevention and treatment of relapse after allogeneic transplantation. Biol Blood Marrow Transplant 2014; 20: 4-13.

21 Porter DL, Alyea EP, Antin JH, DeLima M, Estey E, Falkenburg JH et al. NCI First International Workshop on the Biology, Prevention, and Treatment of Relapse after Allogeneic Hematopoietic Stem Cell Transplantation: Report from the Committee on Treatment of Relapse after Allogeneic Hematopoietic Stem Cell Transplantation. Biol Blood Marrow Transplant 2010; 16: 1467-1503. 